\title{
THE ARABIC COGNATES OR ORIGINS OF PLURAL MARKERS IN WORLD LANGUAGES: A RADICAL LINGUISTIC THEORY APPROACH
}

\author{
Zaidan Ali Jassem \\ Department of English Language and Translation, \\ Qassim University, P.O.Box 6611, Buraidah, KSA \\ Email: zajassems@gmail.com
}

APA Citation: Jassem, Z. A. (2015). The Arabic cognates or origins of plural markers in world languages: a radical linguistic theory approach. Indonesian EFL Journal, 1(2), 144-163

Published: 01-07-2015

\begin{abstract}
This paper traces the Arabic origins of "plural markers" in world languages from a radical linguistic (or lexical root) theory perspective. The data comprises the main plural markers like cats/oxen in 60 world languages from 14 major and minor families- viz., Indo-European, Sino-Tibetan, Afro-Asiatic, Austronesian, Dravidian, Turkic, Mayan, Altaic (Japonic), Niger-Congo, Bantu, Uto-Aztec, Tai-Kadai, Uralic, and Basque, which constitute $60 \%$ of world languages and whose speakers make up $96 \%$ of world population. The results clearly show that plural markers, which are limited to a few markers in all languages comprised of $-s /-a s /-a t$, -en, $-i m,-a /-e /-i /-o /-u$, and $\emptyset$, have true Arabic cognates with the same or similar forms and meanings, whose differences are due to natural and plausible causes and different routes of linguistic change. Therefore, the results reject the traditional classification of the Comparative Method and/or Family Tree Model of such languages into separate, unrelated families, supporting instead the adequacy of the radical linguistic theory according to which all world languages are related to one another, which eventually stemmed from a radical or root language which has been preserved almost intact in Arabic as the most conservative and productive language. In fact, Arabic can be safely said to be the radical language itself for, besides other linguistic features, sharing the plural cognates in this case with all the other languages alone.

Keywords: Plurality, language families and relationships, radical world language, radical linguistic theory
\end{abstract}

\section{INTRODUCTION}

The Radical Linguistic Theory (Jassem $2014 \mathrm{~h}-\mathrm{l}, 2015 \mathrm{a}-\mathrm{i})$ is a slightly revised version which developed from the Lexical Root Theory (Jassem 2012a-f, 2013a-q, and 2014ag). Thus far, it has passed through three main stages. In the initial stage, the lexical root theory was originally proposed to trace back the origins of Indo-European languages into Arabic at all linguistic levels. In particular, Jassem (2012a-f, 2013a-q, 2014a-k, and 2015a-h) has shown in forty three studies that Arabic, English, German, French, and the so-called Indo-European languages as a whole are genetically related very closely phonetically, morphologically, grammatically, and semantically or lexically to such an extent that they can all be regarded as dialects of the same language indeed. More precisely, the Arabic origins or cognates of their words were successfully traced in twenty seven lexical studies in key semantic fields like numerals, religious, love, democratic, military, and legal terms (Jassem 2012a-d, 2013a-q, 2014a-k, 2015a-g); in three morphological studies on inflectional and derivational markers (Jassem 2012f, 2013ab); in nine grammatical papers like pronouns, verb 'to be', wh-questions, and case (Jassem 2012c-e, 2013l, 2014c, 2015d); and in one phonetic study about the English, German, French, Latin, and Greek cognates of Arabic back consonants (Jassem 2013c). In the second stage, it was extended to trace the Arabic origins of pronouns in Mandarin Chinese (Jassem 2014h) and Basque and Finnish (Jassem 2014i). In the final stage (Jassem 2015h-i), it was generalized to trace the Arabic origins of all language families in the areas of demonstrative pronouns (Jassem 2015h) and negation (Jassem 2015i) in eleven major (and minor) language families, making up $95 \%$ of the total world population; plural markers follow suit here. Finally, two 
papers applied the approach to translation studies (Jassem 2014e, 2015b) and one to language learning and teaching (Jassem 2016).

The Radical Linguistic Theory (Jassem $2014 \mathrm{~h}-\mathrm{k}, 2015 \mathrm{a}-\mathrm{i}$ ) is a slight revision of the Lexical Root Theory (Jassem 2012a-f, 2013aq, 2014a-g, 2015a-g), both deriving their name originally from the use of lexical (consonantal) roots or radicals in retracing genetic relationships between words in world languages. The theory first arose as a rejection of the Family Tree Model or Comparative Method in historical linguistics for classifying Arabic as a member of a different language family than English, German, French, Latin, Greek, Sanskrit, and/or the so-called Indo-European languages (see Bergs and Brinton 2012; Algeo 2010; Crystal 2010: 302; Yule 2014; Campbell 2004: 190-191; Crowley 1997: 2225, 110-111; Pyles and Algeo 1993: 61-94). In all the above forty three studies, the very close genetic relationship between Arabic and such languages was, on the contrary, categorically established phonetically, morphologically, grammatically, and semantically or lexically so much so that they can be really considered dialects of the same language, where Arabic was found to be their source or parent language for several reasons (Jassem (2012a-f, 2013a-q, 2014a-k, 2015ag). In other words, Arabic, English, German, and French words of all types and sorts, for example, were shown to be true cognates with similar or identical forms and meanings, whose apparent differences are due to natural and plausible causes and diverse routes of linguistic change. This entails that all such languages developed, in fact must have developed, from an earlier single, perfect, suddenly-emerged Radical or Root Language from which all human languages emanated in the first place, and which could never have died out and will never do so but rather has fully, though variably, survived into today's languages, to which they can all be traced, with Arabic in particular being the closest or most conservative and productive descendant with a continued, unbroken history.

In addition, the traditional classification of language families was found to be grossly inaccurate. Evidence from pronouns in Chinese (Jassem 2014h) and Basque and Finnish (Jassem 2014i) as well as Indo-European pronouns (Jassem 2012c) supports this claim, which shows that all such pronouns have true Arabic cognates or origins. Therefore, to aptly capture the close genetic linkage between European and Arabian languages in general, a new larger language family grouping has been proposed, called Eurabian or Urban (Jassem 2015c: 41; 2015d). On a more global level, a radical (root) world language has also been proposed.

This paper is a follow-up to Jassem's (2015h-i) investigation of the Arabic origins and/or cognates of demonstratives and negation in world languages. In particular, it examines the Arabic origins or source cognates of plural markers in 60 world languages, comprising $61 \%$ of world languages spoken by $96 \%$ of world population (see Table 1 below). The remainder of the paper includes five sections: (ii) research methods, (iii) plural marker survey, (iv) results, (v) discussion, and (vi) conclusion.

\section{METHOD}

\section{The Data}

The Language Sample

The data consists of plural markers in 60 world languages in 14 major and minor language families. These languages are shown in the following table by family and language and speaker statistics.

Table 1. A statistical summary of world languages

\begin{tabular}{lll}
\hline Language Family & No. \& \% of Languages & No. \& \% of Speakers \\
\hline Afro-Asiatic & $366(5.15 \%)$ & $380,821,999(6.05 \%)$ \\
\hline Indo-European & $437(6.15 \%)$ & $1,913,575,380(46.31 \%)$ \\
\hline Sino-Tibetan & $453(6.38 \%)$ & $1,268,181,584(20.16 \%)$ \\
\hline Austronesian & $1223(17.22 \%)$ & $323,456,908(5.14 \%)$ \\
\hline
\end{tabular}




\begin{tabular}{lll}
\hline Altaic (Japonic) & $14(0.20 \%)$ & $206227820(3.28 \%)$ \\
\hline Mayan & $31(0.44 \%)$ & $6,522,182(0.10 \%)$ \\
\hline Dravidian & $84(1.18 \%)$ & $229,346,860(3.65 \%)$ \\
\hline Niger-Congo & $1524(21.46 \%)$ & $436,814,956(6.94 \%)$ \\
\hline Uto-Aztec & $58(0.82 \%)$ & $1,910,442(0.03 \%)$ \\
\hline Turkic & $39(0.55 \%)$ & $170,156,603(2.70 \%)$ \\
\hline Tai-Kadai & $94(1.32 \%)$ & $80,772,252(1.28 \%)$ \\
\hline Basque & 1 & 545,872 \\
\hline Total & $4331(60.84 \%)$ & $95.64 \%$ \\
\hline
\end{tabular}

Source: ethnologue.org 2015

It can be clearly seen in the table that these languages comprise about $61 \%$ of world languages which are spoken by around $96 \%$ of the world population. It also shows that the language families differ in their numbers and speaker populations. More precisely, the largest language families in terms of their native speaker numbers are the Indo-European and Sino-Tibetan whereas the largest in terms of language numbers are the Niger-Congo and Austronesian. Afro-Asiatic languages are about equally divided as to the ratio of speaker and language numbers. All the other language families are minor ones like Altaic, Dravidian, Uto-Aztec, Turkic, and Tai-Kadai. Basque is an isolate without relatives although it has been found to be genetically related to Arabic, Finnish, and Indo-European languages (Jassem 2014i).

\section{Data sources}

Plural marker data selection and/or collection has been obtained from published internet sources about world languages such as www.learn101.org, www.walsonline.org, www.mylanguages.org, www.en.wikipedia.org, and the author's knowledge of and works on Arabic, English, German, French, and European languages (e,g., Jassem 2012f, 2013a-b, 2015d). A brief survey is given separately in section ( 3 ) below.

As for etymological data, all references to English and Indo-European languages are for Harper (2015). However, this etymology is not, like all other similar dictionaries, without its severe drawbacks owing to the many unknowns, uncertainties, and the seemingly illogical derivations or meanings of many words (Jassem 2015h-i). Therefore, it has to be used with discretion.
Concerning Arabic data, the main sources are (Jassem 2012f, 2013a-b, 2015d), Ibn Manzoor (2013), Alghalayini (2010), Alafaghani (2003), e-sources, and the author's knowledge and use of Shami (Syrian) Arabic as a native speaker. All the genetic linkages between Arabic and such languages are exclusively mine, unless otherwise stated.

\section{Data transcription}

In transcribing the data, normal Romanized spelling is used for all languages for practical purposes. Nonetheless, certain symbols were used for unique Arabic sounds: namely, /2 \& 3/ for the voiceless and voiced pharyngeal fricatives respectively, /kh \& gh/ for the voiceless and voiced velar fricatives each, /q/ for the voiceless uvular stop, capital letters for the emphatic counterparts of plain consonants /T (t), D (d), Dh (dh), \& S (s)/, and /'/ for the glottal stop (Jassem 2013c). Long vowels in Arabic are usually doubledi.e., /aa, ee, \& oo/. Numerals indicate tone marks in tone languages like Chinese without considering them in the analysis for having no semantic impact on the final output.

\section{Data Analysis}

Theoretical framework: Radical linguistic theory

In data analysis, the Radical Linguistic Theory (Jassem 2014h-l, 2015a-i), which is a slightly revised and more generalized version of the original lexical root theory (Jassem 2012a-f, 2013a-q, 2014a-g), will be used as the theoretical framework here. The lexical root theory (Jassem 2012a-f, 2013a-q, 2014ag) was so called because of employing the lexical (consonantal) roots or radicals in examining genetic relationships between words such as the derivation of observation 
from serve (or simply srv) (see Jassem 2013o) and description (subscription, prescription, inscription) from scribe (scrb) (see Jassem 2013i, 2014e). The main reason for that is because the consonantal root carries and determines the basic meaning of the word irrespective of its affixation and vowels such as observation (srv). Historically speaking, classical and modern Arabic dictionaries (e.g., Ibn Manzoor 1974, 2013) used consonantal roots in listing lexical entries, a practice first founded by Alkhaleel, an $8^{\text {th }}$ century Arabic linguist, lexicographer, musician, and mathematician (Jassem 2012e).

The lexical root theory has a simple structure, which consists of a theoretical principle or hypothesis and five practical procedures of analysis. The principle states that:

Arabic and English as well as the socalled Indo-European languages are not only genetically related but also are directly descended from one language, which may be Arabic in the end. In fact, it claims in its strongest version that they are all dialects of the same language, whose differences are due to natural and plausible causes and different courses of linguistic change.

In the radical linguistic theory, the above principle has been slightly revised to read:

All human languages are genetically related, which eventually emanated from a single, perfect, suddenlyemerged language which developed over time into countless human dialects and languages that continue to become simpler and simpler. That original first language, which may be called Radical or Root Language, has not died out at all but has instead survived uninterruptedly into modern day languages to various degrees where some languages have preserved words and forms more than others. Perhaps Arabic, on spatial and temporal grounds, has preserved almost all of its features phonetically, morphologically, syntactically or grammatically, and semantically or lexically.
As to the five applied procedures of the lexical root theory which have been used all along to empirically prove that principle in data collection and analysis, they remain the same in the current revised and generalized version: i.e., (a) methodological, (b) lexicological, (c) linguistic, (d) relational, and (e) comparative/historical. Since all have been reasonably described in the above studies (Jassem 2012a-f, 2013a-q, 2014a-g), a brief summary will suffice here.

Firstly, the methodological procedure concerns data collection, selection, and statistical analysis. Apart from loan words, all language words, affixes, and phonemes are amenable to investigation, and not only the core vocabulary as is the common practice in the field (Crystal 2010; Pyles and Algeo 1993: 76-77; Crowley 1997: 88-90, 175-178). However, data selection is practically inevitable since no single study can accomplish that at one time, no matter how ambitious it might be. The most appropriate method for approaching that goal would be to use semantic fields such as the present and the above topics. Cumulative evidence from such findings will aid in formulating rules and laws of language change at a later stage (cf. Jassem 2012f, 2013a-f, 2013l). The statistical analysis employs the percentage formula (see 2.2.2 below).

Secondly, the lexicological procedure is the initial step in the analysis. Words are analyzed by

(i) Deleting affixes (e.g., explained $\rightarrow$ plain),

(ii) Using primarily consonantal roots or radicals (e.g., plain $\rightarrow$ pln), and

(iii) Searching for correspondence in meaning on the basis of word etymologies and origins as a guide (e.g., Harper 2014), which should be used with discretion, though. Starting with meanings, soundless or sound laws, which are central as the former are more stable and change very much less than the latter which do so extensively.

So the final outcome yields the derivation of plain form Arabic baien, baan (v) 'clear, plain' via /l/-insertion or split from /n/ (Jassem 2013i).

Thirdly, the linguistic procedure handles the analysis of phonetic, 
morphological, grammatical and semantic structures and differences between words. The phonetic analysis examines sound changes within and across categories. More precisely, consonants may change their place and manner of articulation as well as voicing. At the level of place, bilabial consonants $\leftrightarrow$ labio-dental $\leftrightarrow$ dental $\leftrightarrow$ alveolar $\leftrightarrow$ palatal $\leftrightarrow$ velar $\leftrightarrow$ uvular $\leftrightarrow$ pharyngeal $\leftrightarrow$ glottal (where $\leftrightarrow$ signals change in both directions); at the level of manner, stops $\leftrightarrow$ fricatives $\leftrightarrow$ affricates $\leftrightarrow$ nasals $\leftrightarrow$ laterals $\leftrightarrow$ approximants; and at the level of voice, voiced consonants $\leftrightarrow$ voiceless. For example, /t/ may turn into /d/ by voice or /th \& s/ by manner.

In similar fashion, vowels change as well. Although the number of vowels differ greatly within and between, e.g., English (Roach 2008; Celce-Mercia et al 2010) and Arabic (Jassem 2012g, 1987, 1993), all can be reduced to three basic long vowels- /a: (aa), i: (ee), \& u: (oo)/ (and their short versions besides the two diphthongs /ai (ay)/ and /au (aw)/ which are a kind of /i:/ and /u:/ respectively). They may change according to modifications in (i) tongue part (e.g., front $\leftrightarrow$ centre $\leftrightarrow$ back), (ii) tongue height (e.g., high $\leftrightarrow$ mid $\leftrightarrow$ low), (iii) length (e.g., long $\leftrightarrow$ short), and (iv) lip shape (e.g., round $\leftrightarrow$ unround). In fact, the vowels can be, more or less, treated like consonants where /i:/ is a kind of $/ \mathrm{j}(\mathrm{y}) /$, /u:/ a kind of /w/, and /a:/ a kind of /h/ or vice versa. Their functions are mainly (i) phonetic such as linking consonants to each other in speech and (ii) grammatical like indicating tense, word class, and number (e.g., sing, sang, sung, song; $\mathrm{man} / \mathrm{men}$ ). Thus their semantic weight is marginal and so is of little lexical significance, if not at all. For these reasons, vowels may be totally ignored in the analysis because the limited nature of the changes do not affect the final semantic result at all.

Sound changes result in natural and plausible processes like assimilation, dissimilation, deletion, merger, insertion, split, reordering, substitution, syllable loss, re-syllabification, consonant cluster reduction or creation and so on. In addition, sound change may operate in a multidirectional, cyclic, and lexically-diffuse or irregular manner (for detail, see Jassem 2012a-f, and 2013c).

Regarding the morphological and grammatical analyses, some overlap obtains. The former examines the inflectional and derivational aspects of words in general (Jassem 2012f, 2013a-b); the latter handles grammatical classes, categories, and functions like pronouns, determiners, verbs, nouns, prepositions, question words, and case (Jassem 2012c-e, 2013l, 2014b-c, 2015d). Since their influence on the basic meaning of the lexical root is marginal, inflectional and derivational morphemes may also be ignored altogether. As both morphological and grammatical features have already been dealt with in full, there is no need to include them in every single case later.

As for the semantic analysis, meaning relationships between words are examined, including lexical stability, multiplicity, convergence, divergence, shift, split, change, and variability. Stability means that word meanings have remained constant over time. Multiplicity denotes that words might have two or more meanings. Convergence means two or more formally and semantically similar Arabic words might have yielded the same cognate in English. Divergence signals that words became opposites or antonyms of one another. Shift indicates that words switched their sense within the same field. Lexical split means a word led to two different cognates. Change means a new meaning developed. Variability signals the presence of two or more variants for the same word (for detail, see Jassem 2012a-f).

Fourthly, the relational procedure accounts for the relationship between form and meaning in words from three angles:

(i) formal and semantic similarity (e.g., three, third, tertiary and Arabic thalath 'three' (Damascus Arabic talaat (Jassem 2012a)),

(ii) formal similarity and semantic difference (e.g., ship and sheep (Jassem $2012 \mathrm{~b})$, and

(iii) formal difference and semantic similarity (e.g., quarter, quadrant, carat, cadre and Arabic qeeraaT 'a fourth; carat' (Jassem 2012a)). 
As in the morphological and syntactic or grammatical procedures, there is no need to tackle it in every single case for it will lead to undesirably lengthy treatments.

Finally, the comparative historical analysis compares every word in English in particular and German, French, Greek, Latin, and Sanskrit in general with its Arabic counterpart or cognate phonetically, morphologically, and semantically on the basis of its history and development in English (e.g., Harper 2014; Pyles and Algeo 1993) and Arabic (e.g., Ibn Manzour 2013; Altha3aalibi 2011; Ibn Seedah 1996) besides the author's knowledge of both Arabic as a first language and English as an equal second language. Discretion should be exercised here due to uncertainties and inaccuracies, especially in Harper's work, though.

In summary, the most appropriate procedure for genetically relating English and Arabic words, e.g., to each other can be summed up as follows:

(i) select a word, e.g., describe, write, tail, tall, cut, democracy, air,

(ii) identify the source, daughter, and/or sister language meaning (e.g., English or Latin) on the basis of especially word history or etymology. It is essential to start with meanings, not sounds or sound laws because they are more stable and change very much less than the latter which do so extensively; for example, all the sounds of a given word might change beyond recognition while meanings do so in a rather very limited way; so the meaning will lead you to the cognate easily whereas the sounds will get you lost definitely,

(iii) search for the corresponding meaning and form in the target, parent, or reference language (e.g., Arabic), looking for cognates: i.e., sister words with the same or similar forms and meanings, and

(iv) finally explain the differences in form and meaning between the cognates lexicologically, phonetically, morphologically, and semantically as indicated. As a matter of fact, finding the right cognate on the basis of its meaning first often leads you to the ensuing changes automatically.
That is the whole story briefly, simply, and truly. No fuss, no mess (see Jassem 20122015).

\section{Statistical analysis}

The percentage formula will be used for calculating the ratio of cognate words or shared vocabulary (Cowley 1997: 173, 182), which has been fully described in earlier papers (Jassem 2012a-f, 2013a-q, 2014a-k).

\section{Plurality in world languages: A linguistic survey \\ World languages of all families not} only mark their plurals in similar or identical ways generally but also have a very limited number of such markers, not exceeding six broad types at the most. The following survey is for 60 languages in 14 major and minor language families which, as stated earlier, constitute $61 \%$ of world languages and $96 \%$ of world population. Their plural forms are listed below by family and language.

\section{Afro-Asiatic Languages}

Afro-Asiatic languages mark plurals similarly. Arabic, the major language in the group, marks its plurals in various ways, which are linked to gender and case. In brief, there are two types of plural in Arabic: regular and irregular, both of which are productively used. While the latter exhibits internal and external vocalic changes which may involve prefixes, infixes, and suffixes like walad 'boy' versus its four plural forms 'awlad, wildan, wild, and wilda( $t$ ) (pronounced wildah at pause, also realized as wildeh, wilde, wildee in spoken Arabic, depending on accent), 'boys', the former is divided into masculine and feminine forms. Masculine plural is usually made by adding the nominative suffix -oon or its accusative variant -een to singular nouns such as muslim 'a Muslim' v. muslimoon 'Muslims- nom.' or muslimeen 'Muslims- acc.' whereas feminine plural by suffixing - at to singular feminine nouns like kaas 'cup' v. kaasat 'cups', bint 'girl' v. banat 'girls'. It has to be noted that the $-n$ can be deleted in certain grammatical (usually genitive) constructions, which need not concern us here (for further details, see Jassem 2012f). 
The other languages in the family have two or three forms at most. For example, Akkadian uses two forms only which are linked to gender and case: (i) $-\bar{u} /-i$ in the masculine as in šarr-um 'king- nom.' v. šarr- $\bar{u}$ 'kings- nom.' and šarr-i 'kingsacc./gen.' and (ii) -um/-im in the feminine as in šarr-at-um 'queen- nom.' v. šarr-āt-um 'queens- nom.' and šarr-āt-im 'queensacc./gen.' (en.wikipedia.org 2015).

Hebrew usually utilizes two plural, gender-based suffixes: (i) -im for masculine nouns as in davar 'thing' v. davarim 'things', jeled 'boy' v. jeledim 'boys' and (ii) -ot for feminine ones as in mita 'bed' v. mitot 'beds' (en.wikipedia.org 2015).

Syriac employs the plural suffix -in with all types of nouns as in tannoor 'oven' $\mathrm{v}$. tannoorin 'ovens', šeqle 'tax' v. šeqlin 'the taxes' and šeqlay 'taxes of' (en.wikipedia.org 2015). As in Arabic, the $-n$ is deleted in genitive constructions.

Amharic makes use of two forms: (i) $\check{c} e$ is the commonest for all noun types as in farase 'horse' v. farasoče 'horses', beta 'house' v. betoča 'houses', seta 'woman' v. setoča 'women'; (ii) -te is less common as in masehafe 'book' v. masehafeta 'books' (Learn101.org 2015).

Coptic uses - wa for all nouns as in $p e-$ ro:me 'the-man' v. pe-ro:mwa 'the-men' (en.wikipedia.org 2015).

Hausa employs several suffixes, which are (i) -una/-ani as in kaf'cup' v. kafuna 'cups', fulawa 'flower' v. furanni 'flowers', (ii) -ai as in littafe 'book' v. littafai 'books', (iii) $w a$ as in itace 'tree' v. itatuwa 'trees', (iv) -ci as in mota 'car' v. motoci 'cars', (v) -ta as in mace 'woman' v. mata 'women', (vi) -je as in gida 'house' v. gidaje 'houses', and (vii) internal (irregular) vocalic change as in doki 'horse' v. dawaki 'horses' (Learn 101.org 2015).

Berber is similar to Arabic in many respects in having regular and irregular plurals (mylanguages.org 2015). For example, regular plurals add -ne as in oushan 'wolf' v. oushanne 'wolves', yisse 'horse' v. yissane 'horses'; irregular plurals involve internal vocalic change just like Arabic as in nmare 'a tiger' v. nmoura 'tigers', ikarde 'monkey' v. ikourda 'monkeys' (All such words have Arabic cognates, e.g., nimr and numoor).

\subsection{Altaic Languages}

In Japanese and Korean, plurality is usually not indicated in both. That is, Korean usually affixes nothing as in keob 'cup, cups', namja 'man, men', jib 'house, houses', amso 'cow, cows' (Learn101.org 2015). However, it sometimes uses the plural suffix deur (deul) as in mal 'horse' v. mal deur 'horses', gae 'dog' v. gae deur 'dogs' (mylanguages.org 2015).

Similarly, Japanese uses nothing as in kорри 'cup, cups', ie 'house, houses', ushi 'cow, cows'; however, in human nouns, the plural suffix tachi or its variant -tati may be added as in josei 'woman' v. josei tachi 'women', dansei 'man' v. dansei tachi 'men', gakusei 'student' v. gakusei-tati 'students', watasi 'I' v. watasi-tati 'we' (Learn101.org 2015).

\subsection{Austronesian Languages}

Different strategies are used in marking their plurals. Malay and Sundanese both repeat the noun twice as in buku 'book' v. bukubuku 'books' (Learn101.org 2015).

Javanese usually attaches nothing to nouns as in buku 'book, books', montor 'car, cars', negara 'country, countries', basa 'language, languages', wong wadon 'woman, women', wong lanang 'man, men'; however, repeating the noun may be used in animal names as in sapi 'cow' v. sapi-sapi 'cows' (Learn101.org 2015).

Tagalog uses the prefix $m g a$ as in puno 'tree' v. mga puno 'trees', libro 'book' v. mga libro 'books' (Learn101.org 2015).

Maori plural is indicated in various ways by means of the definite article, demonstrative pronouns, possessives, and vowel lengthening, e.g., te rakau 'the tree' v. nga rakau 'the trees', wahine 'woman' v. waahine 'women' (en.wikipedia.org 2015).

\subsection{Indo-European Languages}

The largest family in speaker numbers the world over, their plural, which is often linked to gender and case, is marked differently and variously as has already been described in detail in Jassem (2012f, 2015d). Below is a brief exposition, though. 
(i) In Germanic languages, English uses (i) - $s$ often as in cat, cats, (ii) -en sometimes as in ox, oxen, and (iii) irregular plural rarely as in man, men; cow, kine; fox, vixen. German uses (i) -en mainly as in Student v. Studenten, Frau 'woman' v. Frauen 'women', Mensch 'man in general' v. Menschen 'men in general', Tasse 'cup' v. Tassen 'cups', (ii) final vowel addition as in Kuh 'cow' v. Kühe 'cows', Pferd 'horse v. Pferde 'horses', and (iii) irregular plurals as in Buch 'book' v. Bücher 'books', Mann v. Männer 'men', Haus v. Häuser 'houses'.

(ii) In Romance languages, vocalic changes in all are usually applied. Latin, the main language, links plurality to gender and case. In nominative masculine singular $u s$-terminated nouns, $-i$ is used such as stimulus v. stimuli, filius 'boy' v. filii 'boys'; in nominative neuter singular umfinal nouns, $-a$ applies such as pomum 'apple' v. poma 'apples'; and in nominative feminine singular $a$-final nouns, $-e$ is used as in femma 'woman' v. femmae 'women', formula v. formulae. In the accusative, -as is used in the neuter as in pomas 'apples- acc.' and in the feminine as in femmas 'women- acc.'. Other endings are used in the other cases which are not important here (see Jassem 2012f, 2015d).

French, Portuguese and Spanish plural adds $-s$ to all nouns (learn101.org 2015). For example, Spanish hombre 'man' v. hombres 'men'; mujer 'woman' v. mujeres 'women'; casa 'house' v. casas 'houses'; taza 'cup' v. tazas 'cups'; caballo 'horse' v. caballos 'horses'; vaca 'cow' v. vacas 'cows'.

Italian plural involves final vowel change of the $-e /-i$-type in all nouns as in uomo 'man' v. uomini 'men'; donna 'woman' v. donne 'women' v. casa 'house' v. case 'houses'; tazza 'cup' v. tazze 'cups'; cavallo 'horse' v. cavalli 'horses'; mucca 'cow' v. mucche 'cows' (learn101.org 2015). Romanian plural is similar in general (learn101.org 2015).

(iii) In Slavic languages, Russian plural is made by suffixing $-i /-a$ as in dom 'house' v. doma 'houses', korova 'cow' v. korovi 'cows', zhenshina 'woman' v. zhenshini 'women', moozchina 'man' v. moozchini 'men' (learn101.org 2015).

Ukrainian, Polish, Czech, and Macedonia plurals use a similar strategy to Russian in which the plural suffix is $-i$ or $-a$ (learn101.org 2015). For example, Czeck dom 'house' v. domy 'houses', krava 'cow' v. kravy 'cows', zena 'woman' v. zeny 'women', muzh 'man' v. muzhi 'men' (learn101.org 2015).

(iv) In Indo-Aryan languages, Persian uses two suffixes: (i) ha in objects and nonhumans as in kitab 'book' v. kitabha 'books', kul 'flower' v. kulha 'flowers', kaw 'cow' v. kawha 'cows'; and (ii) -an in humans as in mard 'man' v. mardan 'men', zan 'woman' v. zanan 'women'.

Sanskrit uses -(a)s (see Jassem 2012f, 2015d), whose modern direct descendants are Hindi and Urdu (see below).

Kurdish utilises two suffixes: (i) $-a n$ in humans as in pyaw 'man' v. pyawan 'men', zhin 'woman' v. zhinan 'women', and (ii) -kan in objects and non-humans as in kteb 'book' v. ktebkan 'books', gwl 'flower' v. gwlkan 'flowers', dar 'tree' v. darekan 'trees'.

Bengali employs two suffixes also: (i) -ra in human noun plurals as in mahila 'woman' v. mahilara women' and (ii) gulo with all others as in kappa 'cup' v. kappagulo 'cups', garu 'cow' v. garugulo 'cows'.

Urdu uses three forms, which are (i) in/un in objects and humans as in kitab 'book' v. kitabin 'books', karu 'car' v. karin 'cars', biala 'cup' v. bialian 'cups', 3awrat 'woman' v. khawatin 'women', darkhat 'tree' v. darkhatun 'trees', (ii) -at as in makan 'house' v. makanat 'houses', and (iii) zero (no change) as in Adami 'man, men' and $k a^{\prime} i$ 'cow, cows'.

Like Urdu, Hindi uses three forms: (i) -en/-on, e.g., mhilaa 'woman' v. mhilaaen 'women', ghr 'house' v. ghron 'houses', gaaay 'cow' v. gaaayen 'cows', (ii) vowel change as in ghodeaa 'horse' v. ghodee 'horses', and (iii) zero plural (no change) as in aadmi 'man' v. aadmi 'men', $k p$ 'cup' v. $k p$ 'cups' (learn101.org 2015). 
Pashtu makes use of two forms: (i) nah as in kor 'house' v. koronah 'houses', aas 'horse' v. aasoneh 'horses' and (ii) final vowel change as in bialah 'cup' v. biala 'horses', ghawa 'cow' v. ghawawa 'cows', sara 'man' v. sari 'men' (learn101.org 2015).

Punjabi uses three suffixes: (i) $-a m$ as in aurata 'woman' v. auratam 'women', gam 'cow' v. gamiam 'cows', (ii) vowel change as in ghora 'horse' v. ghore 'horses', and (iii) zero plural as in marada 'man, men', ghara 'house, houses' (learn101.org 2015).

(v) In Hellenic languages, Modern Greek plural, like Ancient Greek in general, adds (i) $-s$ as in yenaika 'woman' v. yenaikes 'women', ayelatha 'cow' $\mathrm{v}$. ayelathas 'cows', (ii) involves vocalic change or addition as in anthropos 'man' v. anthropoi 'men', spiti 'house' v. spitia 'houses', flitzani 'cup' v. flitzania 'cups', aloyo 'horse' v. aloya 'horses' (learn101.org 2015). Neuter nouns turn on into $-a$ as in bacterion v. bacteria.

\section{Dravidian Languages}

They have similar plural suffixes. In Tamil, the suffix - gal (sometimes -kkal) is added to nouns which is coupled by changing the last consonant of the noun as well such as malai 'hill, mountain' v. malaigal 'hills'; karam 'hand' v. karangal 'hands'; kan 'eye' v. kangal 'eyes', nilaa 'moon' v. nilaakkal 'moons' (anguagereef.com 2015; learn101.org 2015).

Likewise, Kannada attaches -galu to all kinds of nouns as in karadi 'bear' v. karadigalu 'bears', hasu 'cow' v. hasugalu 'cows', bekku 'cat' v. bekkugalu 'cats' (learn101.org 2015; mylanguages.org 2015).

Malayalam attaches the suffix - $k a l$ to all types of nouns as in patti 'dog', pattikal 'dogs'.

Telugu suffixes -lu to all nouns as in aavu 'cow' v. aavulu 'cows', manisi 'man' v. manisilu 'men', kappu 'cup' v. kappulu 'cups' (learn101.org 2015)

\section{Mayan Languages}

This is a small family, which indicates their plurals differently. For instance, Yucatec uses three forms: (i) unmarked or zero plural, (ii) the suffixes $-o o b$ or $-o b$ where the former is used with nouns that end in a consonant while the latter in a vowel as in $n a$ 'house' v. $n a o b$ 'houses', and (iii) the suffix $-i$ as in $a c$ 'turtle' v. aci 'turtles', cay 'a fish' v. cayi 'fish', nal 'a corn' v. nali 'corn' (Bolles 2001/2015).

Tzotzil uses the suffixes $-e t-i k$ as in mut 'bird' v. mut-et-ik 'birds'; its variants - $t$-ik $(-i k)$ and $-t$-ak are used in possessives (en.wikipedia.org 2015).

\subsection{Niger-Congo Languages}

It has the most languages, numerically speaking, in which plurality is marked differently. For example, Yoruba adds awon before all noun types as in arabirin 'woman' v. awon arabirin 'women', ife 'cup' v. awon ife 'cups', esin 'horse' v. awon esin 'horses' (Learn101.org 2015).

Igbo employs two frontal markers: (i) umu is placed before human nouns as in nwanyi 'woman' v. umu nwayni 'women' and (ii) otutu before all others as in iko 'cup' v. otutu ikodu 'cups', efi 'cow' v. otutu efi 'cows' (Learn101.org 2015).

\section{Bantu Languages}

These are a sub-family of Niger-Congo. For example, Xhosa and Zulu, which are closely related and are the most widely wellknown in the group, use similar strategies in general. Both prefix $i$ - in objects as in incwadi 'book', iincwadi 'books', inkomo 'cow', iinkomo 'cows'. Humans and animals have the prefixes ama- and aba- as in umfazi 'woman' v. abafazi 'women', indoda 'man' v. amadoda 'men', ihashe 'horse' v. amahashe 'horses' (Learn101.org 2015).

Besides, Zulu uses the prefix iz- to mark the plural of objects and animals as in indlu 'house' v. izindlu 'houses', imoto 'car' v. izimoto 'cars', imbali 'flower' v. izimbali 'flowers', inkomo 'cow' v. iziinkomo 'cows' (Learn101.org 2015).

\section{Sino-Tibetan Languages}

The second largest family in terms of speaker numbers, Sino-Tibetan languages, marks plurals similarly. For example, Mandarin, the largest and biggest of all, suffixes - men to nouns and pronouns as in wo 
'I' v. wo-men 'we', xuesheng 'student' v. xuesheng-men 'students'. In most cases, nothing is added to nouns like mă 'horse, horses'. To make up for the loss, numbers (e.g., 1, 2, 3) are often added before nouns (learn101.org 2015; mylanguages.org 2015).

In Burmese, myar is added to all nouns as in nwar 'cow' v. nwar myar 'cows', ain 'house' v. ain myar 'houses' (Learn101.org 2015).

\section{Turkic Languages}

This is a rather small family, all whose plurals are similarly marked. For example, Turkish, the main language, adds the plural suffix -ler/-lar to all nouns as in ev 'house' v. evler 'houses', kahve 'coffee' v. kahveler 'coffees', kitap 'book' v. kitaplar 'books' (Www.cromwell-intl.com. 2015; Learn101.org 2015).

Similarly, Uzbek uses the same suffix in all noun types as in ayyol 'woman' v. ayyollar 'women', moshina 'car' v. moshinlar 'cars' (mylanguages.org 2015) and so do Azeri and Kazakh as in kamera 'a camera' v. kameralar 'cameras', teleba 'a student' v. telebeler 'students' (mylanguages.org 2015; learn101.org 2015).

\section{Tai-Kadai Languages}

This is another small family with Thai being the major language. Thai plural is made by adding zero or nothing to singular (especially animal) nouns as in $m a$ 'horse, horses', wиа 'cow, cows' (learn101.org 2015). Sometimes, other suffixes may be used, which need not concern us here.

\section{Uralic Languages}

This is a small family in which different endings are employed. In Finnish, for example, although the plural is linked to case (eleven in number), the two or three most common endings are: (i) -(o)t in the nominative case as in talo 'house' v. talot 'houses', kirja 'book' v. kirjat 'books', (ii) - $a$ in the partitive as in taloja 'houses', (iii) -en in the genitive as in talojen 'house's', and (v)-i/(o) $i$ in $a$-final nouns as in muna 'egg' v. muni 'eggs', kana 'hen' v. kanoi 'hens'. All the other cases take their name from and end with a preposition as in taloissa 'in the houses', taloilla 'on/by house' (learn101.org 2015; mylanguages.org 2015; Venla 2015).

Estonian plural adds - $d$ as in karu 'bear', karud 'bears', kass 'cat', kassid 'cats' (mylanguages.org 2015; learn101.org 2015). Hungarian plural attaches $-k(-a k,-e k)$ as in no 'woman' v. nok 'women', haz 'house' v. hazak 'houses', lo 'horse' v. lovak 'horses' (learn101.org 2015).

\section{Uto-Aztec Languages}

This is a small family where various suffixes are used. In Nahuatl, the plural is formed by adding (i) - meh as in kojo-tl 'coyote; a kind of American wolf; lowly person' v. kojo-meh 'coyotes', (ii) -tin, (iii) reduplication sometimes, (iv) -wan in possessive plurals as in kal-li 'house', no-kal 'my house' v. nokalwan 'my houses' (en.wikipedia.org 2015).

Hopi plural is normally formed by adding (i) $-m$ as in tsiro 'bird' v. tsirom 'birds' or (ii) by reduplication (Grune 1997/2015). (Note Hopi tsiro and Basque txir 'bird' are from Arabic Tair 'bird' via /T/-split into $/ \mathrm{t}(\mathrm{s} / \mathrm{x}) /$.

Yaqui uses -im as well, e.g., miisi 'cat' v. miisim 'cats' (Langendoen and Fabian 2015).

\section{Basque}

Although Basque is considered an isolate without sisters in Europe (Campbell 2006/2013; Crowley 1997), Jassem (2014i) rejected that and established its relationship to both Arabic and Indo-European languages, regrouped and renamed Eurabian or Urban (Jassem 2015f). Anyway, its plural attaches $a k$ to all nouns as in lorea 'flower' v. loreak 'flowers', autoa 'car' v. autoak 'cars'.

\section{RESULTS \& DISCUSSION}

The results will mainly focus on the Arabic lexical (consonantal) radicals or roots of plural markers in world languages and the changes that affected them. As the exact quality of the vowel or tone marks has little or no semantic impact whatsoever on the final output, it will be ignored as usual (Jassem 2012-2015). The results will be presented family by family and language by language, all whose plural markers can be 
traced back to Arabic as a Radical or Root Language directly and easily, though with a little explanation sometimes.

Afro-Asiatic Languages

The Arabic origins and/or source cognates of all their different plural markers can be easily and directly traced back as follows.

a) Akkadian -in (dual), Syriac -in, Berber $n e$, and Hausa -una/-ani are all true and identical cognates to Arabic -een/-oon;

b) Akkadian -im/-um and Hebrew -im could have developed from either (i) Arabic -um 'a plural pronominal marker' as in anta 'you (sing.)' v. antum 'you (pl.)' via morphological shift or (ii) Arabic een/-oon in which $/ \mathrm{n} /$ evolved into /m/.

c) Hebrew -ot, Hausa -ta and -ci, and Amharic -te and -če all come from Arabic - ta in which / $t$ / further developed into /s \& ch/ in Hausa and Amharic; that is, -ta and -ci and -te and če can be really treated as 'conditioned' variants;

d) Akkadian - $u$, Coptic $-w a$, and Hausa - wa derive from Arabic $-o o(n)$ in which $/ \mathrm{n} /$ is deleted in genitive constructions and/or $-o o$ ' $3^{\text {rd }}$ person plural pronominal marker';

e) Hausa - $a i$ and -je, Akkadian - $i$, and Arabic $-e e(n)$ are true and identical cognates in the first of which /-ee/ became $/ \mathrm{j} /$;

f) Hausa irregular plural descends directly from Arabic internal irregular/broken plural as in baaki 'weeper' v. bawaki 'weepers'.

\section{Indo-European Languages}

All their plurals have already been traced back to Arabic roots in Jassem (2012f, 2013a, 2015f) as follows:

a) Case apart, English $-s$, Greek $-s$, Latin $-s$, Portuguese $-s$, Spanish $-s$, French $-s$, Sanskrit $-s$, and Urdu -at all come directly from Arabic - at via its evolution into /s/ as /t (d) \& s/-variation is very common in these languages like democrat, democracy; intimate, intimacy; poetess, Jeanette, Henritta; amat (Latin), liebt (German), loves (English); b) English -en, German -en, Persian -an, Kurdish -an, Urdu -in/-un, Hindi -en/-on, Pashtu -nah, Punjabi - am, Bengali -ra descend straight from Arabic -een/-oon via morphological shift in which /n/ became $/ \mathrm{m} /$ or $/ \mathrm{r} /$ in the last two as $/ \mathrm{n}$ $\& \mathrm{r} /$ are considered variants in IndoEuropean languages as in German and Greek verbal marker -en (e.g., German lieben 'to love') compared to Latin -re and French -er (e.g., Latin amare 'to love');

c) Irregular (and zero) plural forms in English, German, Hindi, Urdu, and Punjabi of all types derive directly from the various Arabic irregular plural forms;

d) Persian - ha descends straight from Arabic $-t$ which became /h/, a common sound process involving final $/ \mathrm{t} /$ at pause in Arabic;

e) Plural forms involving final vowel change of the /-a, -e/-i, \& -o/-u/-type in English, German, Latin, Italian, Greek, Sanskrit, Hindi, Russian, Ukrainian, Polish, Czech, Macedonian, Pashtu, Punjabi, all derive from the same Arabic forms;

f) Kurdish -kan can be analyzed as (i) a combination of the two Arabic plural suffixes $-t$ and -een/-an via morphological shift and passing / $\mathrm{t} /$ into $/ \mathrm{k} /$ or as (ii) a variant of -an/-een into which $/ \mathrm{k} /$ was inserted as a result of /ee/-mutation or palatalization into /k/;

g) Bengali -gulu derives from the same source postulated for Dravidian languages below (3.5).

\section{Altaic Languages}

The main Japanese and Korean zero plurals are similar to some Arabic nouns in this respect like insan 'human' and mar'at 'woman' which lack plural forms altogether but may indicate plurality as well.

Furthermore, after certain numerals like 11100 and 1000, the singular form of Arabic nouns is used as in mi'at rajul 'lit., a hundred man'. In addition, the singular form may indicate the plural, a common linguistic process as in English Man is weak/great, which means all men and women.

As to the Japanese plural markers tachi amd-tati, they can be considered 
variants in which /t/ changed into /ch/. As such, they derive from Arabic - at via reduplication. Korean deul/deur can be similarly treated in which $/ d /$ developed from $/ \mathrm{t} /$ with $/ \mathrm{l} /$ being an insertion or a mutation of $/ \mathrm{n} /$ in accusative $-t$ (in) as in kaasaatin 'cups- acc.'.

\subsection{Austronesian Languages}

The reduplication of nouns in the plural in Malay, Sundanese, and Javanese to a little extent, derives from a very common, similar Arabic process where nouns are repeated in certain contexts as in masha al-awladu fardan fardan 'walked the-boys individual individual- i.e., the boys walked one by one'. Furthermore, Arabic has various strategies for emphatic reduplication by using (i) bilateral verbs like $k a b b$ v. kabkab 'pour out' and (ii) nouns of the same verbs such as masha mashi(an) 'walked walking', katab kitaba(tan) 'write writing'.

As to Javanese zero plural marking, this can be accounted for in the same way as for Korean and Japanese above.

Tagalog mga and Maori nga can be considered variants in which $/ \mathrm{n} /$ developed from $/ \mathrm{n} /$. As such, both derive from (i) the Arabic pronominal plural marker $-m$ into which /g/ was inserted or (ii) -een/-oon via reversal, turning $/ \mathrm{n} /$ into $/ \mathrm{m} /$, /g/-insertion, and morphological shift. As to Maori's vowel lengthening, it is a kind of irregular plural, a common process in Arabic and many other languages above.

\subsection{Dravidian Languages}

All these language use similar or identical forms, which are -gal/-kkal in Tamil, -galu in Kannada, -kal in Malayalam, all simplified to -ulu in Telugu where /g (\& k)/ were dropped. This being so, they can all be considered variants. Consequently, they directly relate to Arabic -at which split into /k (g) \& l/. An alternative route would be the one for Kurdish -kan above in which /(k \&) $\mathrm{n} /$ became /(g \&) l/ (see 3.2f).

\subsection{Mayan Languages \\ Yucatec $-o(o) b$ derives from Arabic - $u$ via /b/-insertion or split from /w/. Yucatec $-i$}

and zero plural both obtain from the same Arabic source cognates as well.

Tzotzil -et-ik and its variants all derive from Arabic $-t$ via reduplication and turning / $\mathrm{t} /$ into $/ \mathrm{k} /$.

\subsection{Niger-Congo Languages}

Yoruba awon comes straight from

Arabic-oon via morphological shift in which it is used as a suffix (see above).

As to Igbo, the first form umu derives from the Arabic pronominal plural marker (u) $m$ via morphological shift or from-oon, turning $/ \mathrm{n} /$ into $/ \mathrm{m} /$ as in Yoruba above. The second marker otutu is derived from Arabic at via reduplication and morphological shift.

\subsection{Bantu Languages}

Zulu $-i z$ can be considered a variant of Arabic $-t$ from which it directly obtains via /t/-mutation into /z/ and morphological shift.

Xhosa $i$ - is taken direct from Arabic $-i$ via morphological shift whereas ama-/aba-, which can be considered variants in which $/ \mathrm{m} /$ became $/ \mathrm{b} /$ or vice versa, descend directly from either (i) the Arabic pronominal plural marker $-(u) m$ via morphological shift or (ii) from -oon, turning $/ \mathrm{n} /$ into $/ \mathrm{m} /$ as in Yoruba and Igbo above.

\subsection{Sino-Tibetan Languages}

Mandarin - men and Burmese myar can be treated as variants in the latter of which $/ \mathrm{n}$ / became $/ \mathrm{r} /$. Viewed thus, both may derive from either (i) the Arabic pronominal plural marker - $(u) m$ via /n/-split from $/ \mathrm{m} /$ and its subsequent evolution into $/ \mathrm{r} /$ in Burmese besides morphological shift or (ii) from -een/-oon via /n/-split into /m \& $\mathrm{n} /$ in one and $/ \mathrm{m} \& \mathrm{r} /$ in the other.

Furthermore, Mandarin zero plural is similar to Japanese and Korean besides other languages, whose Arabic roots have already been stated.

\subsection{Turkic Languages}

All Turkic languages like Azeri, Kazakh, Turkisk, and Uzbek, use the same plural marker -lar/-ler, which can be considered a variant of Arabic -een/-oon and its reflexes in IndoEuropean languages such as English -en via 
/n/-split into /l \& r/. Another route might be Arabic -at, splitting into /l \& r/. No other routes may account for it.

\subsection{Thai-Kadai Languages}

Like Chinese, Japanese, and Korean as well as other languages, the main Thai zero plural markers derive from a similar Arabic process.

\subsection{Uralic Languages}

Finnish -(o)t and Estonian $-d$ can be considered variants, which both come direct from Arabic - $t$, turning it into /d/ in Estonian. As to Finnish $-a,-(o) i$, and $-e n$, they are all taken straight from the same Arabic forms as shown above.

Hungarian $-k(-a k,-e k)$ are all variants, coming directly from Arabic -at via its mutation into $/ \mathrm{k} /$.

\subsection{Uto-Aztecan Languages}

These languages use the same or similar forms. Nahuatl $-m e h$, Hopi $-m$, and Yaqui -im can be regarded as variants via /h/-insertion or deletion. Thus all may be derived from either (i) the Arabic pronominal plural marker $-m$ or (ii) -een/-oon via its mutation into $/ \mathrm{m} /$ plus $/ \mathrm{h} /$-insertion or loss; Nahuatl -tin comes from a combination of two Arabic plural markers $-t$ and -een via morphological shift; Nahuatl -wan is from Arabic-oon/-een, turning /oo/ into /w/; and Nahuatl and Hopi reduplicate plural descends from a similar Arabic process via morphological shift like Malay above.

\subsection{Basque}

Basque $-a k$ is very much akin, in fact identical, to Hungarian $-k(-a k$, $-e k)$, all of which derive from Arabic - at via its mutation into $/ \mathrm{k} /$.

In summary, the total number of language families is 14 with 60 languages, all whose plural markers were traced back to Arabic successfully, easily, elegantly, smoothly, and directly.

It can be clearly seen in the results that plurality is a very common morphological (inflectional) feature in all world languages that is formed in the same or similar ways. That is, plural markers like $-s$, - $a t$, -in, -im, and vocalized in world languages are true cognates for sharing identical or similar forms and meanings, whose differences, however, are all due to natural and plausible causes and different routes of phonetic, morphological, grammatical, and semantic change.

Thus the results give further support to Jassem's (2015i) study of the Arabic origins of demonstrative pronouns and Jassem's (2015j) of negative particles in 112 world languages from 12 language families, all of which had Arabic true cognates. They also back up his studies on the Arabic origins of personal pronouns in Indo-European (Jassem 2012c), Chinese (Jassem 2015h), and Basque and Finnish (Jassem 2014i). In particular, they agree with his investigation of the Arabic roots of Indo-European number and gender markers (Jassem 2012f). On a more general level, indeed, they substantiate Jassem (2012a-f, 2013a-q, 2014a-k, 2015a-g) in which English, German, French, Latin, Greek, Sanskrit and Arabic were all found to be not only members of the same family but also rather dialects of the same language. This led the researcher to generally classify these languages as Eurabian or Urban which is a blend of Indo-European and Arabian languages (Jassem 2015c: 41, 2015d).

In light of the above picture, the results indicate that the traditional classification of world languages into families is grossly inaccurate, furthermore. As languages from different families around the world share a very limited number of the same or similar plural markers or forms- i.e., -en/-an, -im, -s/-as, -t/-ot/otuto, and vocalized plural, this clearly indicates that classifying them into separate, unrelated families is certainly wrong. For example, Arabic - $m$, Akkadian and Hebrew -im, Mandarin men, Burmese myar, Hopi - $m$, Natuatl - $m e h$, and Igbu -imu are all identical cognates, to which Tagalog mga and Maori $n g a$, furthermore, can be added via the replacement of $/ \mathrm{m} /$ by $/ \mathrm{n} /$ and $/ \mathrm{g} /$-insertion. Similarly, Arabic -oon/-een, Akkadian (and Arabic) -in (dual), Syriac -in, Berber - ne, and Hausa -una/-ani, English -en, German -en, Persian -an, Kurdish -an, Urdu -in/-un, Hindi -en/-on, Pashtu -nah, Punjabi -am, Bengali - 
$r a$, Yoruba awon, and Finnish -jen are identical cognates. Another such example is Arabic - at, Hebrew -ot, Hausa -ta and - ci, and Amharic -te and -če, Urdu -at, Tzotzil -et-ik, Finnish -ot, all of which are identical cognates also. Also vocalized and irregular plurals are similar everywhere like Arabic, Latin, Finnish, Russian, and so on. Thus, as can be clearly seen, grouping these languages into separate, unrelated families is certainly wrong.

Now what does all that entail? To begin with, it entails the need for reclassifying world languages on new grounds, which is a "topic of great current interest in historical linguistics" (Cmpbell: 344). One such attempt is Jassem (2015c-d) which grouped Arabic and Indo-European languages into one family, called Eurabian or Urban. Next, this implies by necessity, on a global level, that all human languages descended from a common source language from which, in this particular case, all plural markers, just like demonstrative pronouns, negation, and personal pronouns, in all world languages are derived but are, nevertheless, used selectively and variably where some markers occur in some languages but not in others, for instance. The sheer percentage of shared plural markers between Arabic and the other languages, which amounted to $100 \%$, indicates such descent very clearly (cf. Cowley (997: 172-173).

What is the status of such an ancestral or early common language? This can be answered with reference to the Radical Linguistic Theory which the results support on all theoretical and analytical grounds. Theoretically, the main principle which states that all human languages are genetically related, which descended from a single parent language and survived until today with Arabic and Indo-European languages like English, German, French, Latin, Greek, and Sanskrit being its closest descendants is, therefore, verifiably sound and empirically true. More precisely, all human languages stemmed from an earlier, perfect, suddenlyemerged language, called radical (world) language from which all human languages initially came and which has incessantly and variably survived into today's languages, albeit getting simpler and simpler over time. In other words, the radical language could never have died out and will never do so beyond recognition. With proper methodology, it can be easily recovered and/or identified as already shown in this work (cf. Campbell 2006: 360). As this work clearly demonstrated, it seems that its closest or most conservative and productive descendant is Arabic for sharing all plural markers with the other languages, thus having preserved almost all its features (Jassem 2014h-k, 2015a-d). The next closest languages are European languages on the grounds of geographical proximity: i.e., the geographically nearer, the linguistically and genetically closer. In fact, all Indo-European languages were already found to have descended directly from Arabic (for details, see Jassem 2015a-b, 2015d: 131-132; 2014ab, 2014e).

So, as all the plural markers of all types, like demonstratives and negative particles (Jassem 2015i-j), in all world languages can be easily traced back to Arabic only, it can thus be safely said that Arabic is the common source or the radical word language which has kept it almost intact. The exact time and place of the split-up between Arabic and such languages is immaterial although one can safely say that the original place of the radical language has been where Arabic has continuously been spoken over the ages (for details, see Jassem 2015e-j).

The permanence, sustenance or survival of the radical or root world language has already been established in a number of studies. The first study was Jassem (2015h), which showed that demonstrative pronouns in almost all world languages (96\% of speakers) are shared among them all and which, furthermore, could all be traced back to Arabic. Again this confirms that Arabic has inherited and maintained all the features of the radical world language- i.e., Arabic is the radical language itself. The second evidence came from Jassem (2015j) which manifested that negation in world languages is expressed in a limited number of similar or identical markers or forms, all of which were successfully traced back to Arabic also. The third, though a little more limited, evidence 
has been provided by tracing personal pronouns in Indo-European languages (Jassem 2012c, 2013l), Chinese (Jassem 2014h), and Basque and Finnish (Jassem 2014i) back into Arabic as well. Observations from other world languages such as Mayan exhibit a very close relationship and lead to the same conclusion.

The fourth evidence comes from divine and theological or religious terms like Hallelujah (Halleluiah, Alleluia) which variably occurs in all world languages and is traced back to Arabic (Jassem 2012a, 2o14e). More precisely, Hallelujah derives from a reduced and merged form of Arabic la ilaha illa allah

'(There's) no god but God', where Halle is Allah 'God' in reverse, lu is la 'no', and jah is a reduction and merger of ilaha illa iah 'god but him' via /l \& i/-merger, a common sound process in Arabic and some European languages like Spanish and French.

Besides, further evidence may be derived from the biblical names of ancient prophets and persons like Adam, Eve, Noah, Abraham, Saleh, Hood, Moses, Jesus Christ, Charles, John, Matthew, Paul, Peter, etc. (Jassem 2014f, 2015j). As opposed to other languages, only in Arabic do such names have instantly recognizable meanings and are in currently extensive practice or usage as normal words like nouns, verbs, adjectives, and adverbs (Jassem 2014f, 2015j). Jassem (2015j) adduced three main reasons for postulating a radical or root world language, from which all human languages stemmed and which must have been perfect on all counts. To start with, language acquisition is impossible in isolation and without contact with and exposure to others. In other words, man acquires the language he was born into from his parents, family, and community, regardless of time and place. Without them, man could never speak or utter a single, meaningful word. That is, the first language ever was perfect from its sudden start. That language was then passed down with little changes from generation to generation in the central area of the birthplace of humanity, now commonly called the Middle East. Secondly, as language change involves simplification in the main, it entails that the root language was fuller and more varied. In other words, it had a larger word stock or vocabulary, more word forms or morphemes, and more grammatical endings and/or structures that are variably maintained or preserved in world languages. Finally, because totally new words can never be invented but are rather recombined from existing ones, the radical language must have been completely and fully developed at all linguistic levels: phonetic or phonological, morphological, syntactic, and semantic or lexical.

As a consequence, reconstructing an old world language is needless and/or should agree with an old world language, the best representative of which is Arabic; rather that proto-language, called radical language here, is still very much alive and vibrant, having variably survived into today's languages, with Arabic being its closest descendant as the above data clearly shows (for detail, see Jassem 2014h: 254-256, 2014i: 116-117; $2014 \mathrm{k}, 2015 \mathrm{a}-\mathrm{b})$. Thus the quest should focus on relating those languages to it instead of reconstructing hypothetical, fictitious languages. The above-mentioned evidence from plural markers, negative terms, personal pronouns, religious terms, proper names substantiate that claim. Jassem (20122015) followed that practice in all such studies, in fact.

Now, turning to the analytical level, the procedures of the radical linguistic theory all operated neatly and smoothly on all levels despite their limited occurrence due to the linguistic nature of the plural markers themselves. Phonetically speaking, the sound changes were natural and plausible, cyclic and multi-directional, including processes like substitution, deletion, reversal, merger, split, reordering, reduction, and so on. Morphologically, all inflectional and derivational affixes have true Arabic cognates (for detail, see Jassem 2012f, 2013a-b, 2013l, and 2015d). Furthermore, plural markers have multiple inflectional functions (e.g., person, gender, case) and derivational ones (e.g., nouns, verbs) as happens in Eurabian or Urban languages (Jassem 2012f, Jassem 2013a-b, Jassem 2015d). 
Semantically, morphological stability was the commonest pattern where most plural markers preserved their basic meanings across the languages, e.g., -een/-oon (-en, -in, -an), -um (-im, -m, -meh, -men, myar), -at (-t, otutu, tati), $-s$ (-as), and vocalized plural $(-a,-e /-i,-o /-u)$. The recurrence of morphological convergence in the data was due to formal and semantic similarity between Arabic forms, on the one hand, and their cognates in other languages, on the other. For instance, -m (-im, -meh, -men) might derive from two Arabic formally and semantically similar markers, which are -um and -een (see 4 above). Although only one cognate might be the ultimate source in the end, no need is presently felt to specify which one it might be; the reader may judge. Morphological shift was widespread; it occurred in Zulu and Khosa by moving the plural suffix from end to beginning of word. The same happened in Niger-Congo's Yoruba and Igbo in which it is used a separate word. It also occurred in Arabic - um which moved from a pronominal plural marker to a noun plural marker in Hebrew and Hopi, for example. Morphological divergence was not attested. Morphological split affected Arabic $m a$, which might have resulted in all - $m$-based and $-n$-based affixes, e.g., English -in and Chinese and Burmese -men/myar. Morphological change obtained in all those languages with zero plural like Chinese, Burmese, Japanese, Korean, Thai, Javanese, and so on. Finally, morphological variability recurred in the data, whether at the level of the different forms of the same markers within the same language such as English $-s$ in its different pronunciations like cats, dogs, kisses or across the languages like English $-s$, German - $t$, French - $s$-aux, Latin - $a s$, Finnish $t$, Urdu - at, Arabic - at, Hebrew -ot, Hausa $t a$, Japanese tati, and Igbu otutu (see 4 above and 6.c below). Arabic, in particular, is replete with linguistic variability of all plural types such as the suffixes -oon/-een and -oo/-ee/$a a$ and multiple plurals of the same word (see 3.1 above).

\section{CONCLUSION}

The main findings of this study can be summed up as follows: i) Plural markers in all world languages are true cognates with similar or identical forms and functions, whose differences are due to natural and plausible causes and different routes of linguistic change; all can be reduced to four or five main types- $-s /-t$-based, $m$-based, $n$-based, vowel-based, and unmarked (zero) plural, which can all easily be traced back to Arabic as follows:

a) Arabic-um, Akkadian and Hebrew -im, Punjabi -am, Hopi - $m$, Natuatl -meh, Igbu imu, Mandarin men, and Burmese myar are all identical cognates, to which Tagalog mga and Maori nga can be added via /g/insertion;

b) Arabic-oon/-een, Akkadian -in (dual), Syriac -in, Berber - ne, and Hausa - una/ani, English -en, German -en, Persian an, Kurdish -an, Urdu -in/-un, Hindi en/-on, Pashtu -nah, Bengali - ra, Yoruba awon, and Finnish -jen are identical cognates;

c) Kurdish -kan, Bengali - gulu, Tamil - gal (-kkal), Kannada -gal(u), and Malayalam -ulu might have been brought about by (i) combining Arabic - $t$ and -an/-een into one via /-t \& n/-mutation into /-k (g) \& $\mathrm{l} /$ or (ii) by /t/-split into $/ \mathrm{k}$ (g) \& l/, followed by $/ \mathrm{k} /$-loss in the last.

d) Arabic - at, Urdu - at, Hebrew -ot, Igbu otutu, Hausa -ta and -ci, and Amharic -te and -če, Tzotzil -et-ik, Finnish -ot, and Japanese tati/tachi are identical cognates via reduplication in some and passing / $\mathrm{t}$ / into /s (ch)/ in others; besides, Persian $h a$, Hungarian $-k$, Basque $-a k$, and Zulu iz resulted from turning / $\mathrm{t} /$ into $/ \mathrm{h}, \mathrm{k}, \mathrm{\&}$ $\mathrm{z}$ / in that order plus morphological shift in the last;

e) Noun Reduplication in Malay, Sundanese, and Javanese has true Arabic cognates;

f) Vocalized plurals in all the languages like Latin, Italian, German, and Russian have true Arabic cognates;

g) Irregular plurals in all languages have true Arabic cognates;

h) Turkish, Azeri, Kazakh and Uzbek -lar/ler derive from Arabic -een/-oon or -at, splitting into /l \& r/; and

i) Zero plural in Javanese, Mandarin, Japanese, Korean, Thai, and to a little 
extent, in English, German, Hindi, Urdu, and Punjabi have Arabic cognates.

ii) The radical linguistic theory has been theoretically and analytically adequate for genetically relating plural markers in all world languages to Arabic, which entails that the traditional classification of world languages into separate, unrelated families is grossly mistaken. Theoretically, all these languages initially originated from one language that may be called Radical or Root World Language, which was not only perfect from onset and outset but also has variably survived into today's languages. As Arabic has, besides its phonetic and morphological capacity, variety, and complexity, the largest plural markers compared to those in the other languages, it can be safely said that it has inherited almost all the Radical Language features, thereby showing its incessant permanence as the most conservative of all: i.e., it is the radical language itself.

Analytically, the main phonetic changes were natural and plausible, cyclic and multidirectional, including substitution, insertion, reversal, reordering, split, and merger; lexically, the recurrent patterns were stability, convergence, shift, split, and variability.

iii) Finally, future research is needed to further substantiate the theory and to test its applicability to language teaching, lexicology and lexicography, translation (Jassem 2014d, 2015a), cultural (including anthropological, historical, social, religious) awareness, understanding, and heritage for promoting cross-cultural and global understanding and cooperation in all areas of human life.

\section{ACKNOWLEDGEMENTS}

Sincere thanks are warmly extended to everyone who contributed to this research in any way worldwide. Emeritus Professor Patrick Bennett of the University of Wisconsin at Madison deserves special mention for suggesting casting the comparative net wider and using language mass comparisons and so does Fahrus Zaman
Fadhly, managing editor Indonesian EFL Journal (IEFLJ), for support and feedback. For my supportive and inspiring wife, Amanie M. Ibrahim, I remain indebted as ever.

\section{REFERENCES}

Alafaghani, S. (2003). Almoojaz fi qawa3id allugha al3arabia (In Arabic, A concise Arabic grammar). Damascus: Dar Alfikr.

Algeo, J. (2010). The origins and development of the English language. (6th ed.). Wadsworth Cengage Learning.

Alghalayini, A. S. M. (2010). Jaami3 Al-duroos Al3arabia. Saida and Beirut: Al-Maktabat Al3aSriyat.

Bergs, Alexander and Brinton, L. (eds). (2012). Handbook of English historical linguistics. Berlin: Walter de Gruyter.

Bolles, David and Alejandra. ( 2001). A grammar of the Yucatecan Mayan language: The noun. Lancaster, California: Labyrinthos Press. Retrieved URL http://www.famsi.org (November 13, 2015).

Campbell, L. (2006/2013). Historical linguistics: An introduction. (2nd ed.). Cambridge, Mass.: The MIT Press.

Celce-Murcia, M. et al. (2010). Teaching pronunciation: A course book and reference guide. (2nd ed.). Cambridge: Cambridge University Press.

Crowley, T. (1997). An Introduction to historical linguistics. (3rd ed.). Oxford: Oxford University Press.

Crystal, D. (2010). The Cambridge encyclopedia of language. (3rd ed.). Cambridge: Cambridge University Press.

Ethnologue. (2015). Summary statistics. Retrieved URL: http://www.ethnologue.com/statistics/family (Nov. 3, 2015).

Finnish Grammar- Plural Stem. 2015. Retrieved URL: http://www.jyu.fi (November 3,2015 ).

Grune, D. (1997/2015). Hopi: A survey of Uto-Aztecan languages. Retrieved http://www.dickgrune.com (November 11, 2015).

Harper, D. (2015). Online etymology dictionary. Retrieved http://www.etymonline.com (Nov. 3, 2015).

Jassem, Z. A. (1987). Phonological variation and change in immigrant speech: A sociolinguistic study of a 1967 Arab-Israeli war immigrant speech community in Damascus, Syria. PhD Thesis, Durham University, UK. Retrieved http://etheses.dur.ac.uk/1682/1/1682.pdf (Nov. 3, 2015)

Jassem, Z. A. (1994a). Impact of the Arab-Israeli wars on language and social change in the Arab world: The case of Syrian Arabic. Kuala Lumpur: Pustaka Antara.

Jassem, Z. A. (1994b). Lectures in English and Arabic sociolinguistics, 2 Vols. Kuala Lumpur: Pustaka Antara.

Jassem, Z. A. (2012a). The Arabic origins of numeral words in English and European languages. 
International Journal of Linguistics 4 (3), 225-41. Retrieved URL:

http://dx.doi.org/10.5296/ijl.v4i3.1276 (Nov. $3,2015)$.

Jassem, Z. A. (2012b). The Arabic origins of common religious terms in English: A lexical root theory approach. International Journal of Applied Linguistics and English Literature 1 (6), 59-71. Retrieved URL:

http://dx.doi.org/10.7575/ijalel.v.1n.6p.59 (Nov. 3, 2015).

Jassem, Z. A. (2012c). The Arabic origins of English pronouns: A lexical root theory approach. International Journal of Linguistics 4 (4), 83-103. Retrieved URL:

http://dx.doi.org/10.5296/ijl.v4i4.227 (Nov. 3, 2015)

Jassem, Z. A. (2012d). The Arabic origins of determiners in English and European languages: A lexical root theory approach. Language in India 12 (11), 323-359. Retrieved URL:

http://www.languageinindia.com (Nov. 3, 2015)

Jassem, Z. A. (2012e). The Arabic Origins of Verb "To Be" in English, German, and French: A Lexical Root Theory Approach. International Journal of Applied Linguistics and English Literature 1 (7), 185-196. Retrieved URL:

http://dx.doi.org/10.7575/ijalel.v.1n.7p.185 (Nov. 3, 2015).

Jassem, Z. A. (2012f). The Arabic origins of number and gender markers in English, German, French, and Latin: a lexical root theory approach. Language in India 12 (12), 89-119. Retrieved URL: http://www.languageinindia.com (Nov. 3, 2015)

Jassem, Z. A. (2013a). The Arabic origins of derivational morphemes in English, German, and French: A lexical root theory approach. Language in India 13 (1), 48-72. Retrieved URL:

http://www.languageinindia.com (Nov. 3, 2015).

Jassem, Z. A. (2013b). The Arabic origins of negative particles in English, German, and French: A lexical root theory approach. Language in India 13 (1), 234-48. Retrieved URL: http://www.languageinindia.com (Nov. 3, 2015).

Jassem, Z. A. (2013c). The English, German, and French cognates of Arabic back consonants: A lexical root theory approach. International Journal of English and Education 2 (2): 108-128. Retrieved URL: http://www.ijee.org (Nov. 3, 2015).

Jassem, Z. A. (2013d). The Arabic origins of "water and sea" terms in English, German, and French: A lexical root theory approach. Language in India 13 (2): 126-151. Retrieved URL: http://www.languageinindia.com (Nov. 3, 2015).

Jassem, Z. A. (2013e). The Arabic origins of "air and fire" terms in English, German, and French: A lexical root theory approach. Language in India 13 (3): 631-651. Retrieved URL: http://www.languageinindia.com (Nov. 3, 2015).

Jassem, Z. A. (2013f). The Arabic origins of "celestial and terrestrial" terms in English, German, and French: A lexical root theory approach. International Journal of English and Education 2 (2): 323-345. Retrieved URL: http://www.ijee.org (Nov. 31, 2015).

Jassem, Z. A. (2013g). The Arabic origins of "animal" terms in English and European languages: A lexical root theory approach. Language in India 13 (4): 68-106. Retrieved URL: http://www.languageinindia.com (Nov. 1, 2015).

Jassem, Z. A. (2013h). The Arabic origins of "body part" terms in English and European languages: A lexical root theory approach. International Journal of Current Applied Linguistics and English Literature (1). Retrieved URL: http://www.bretj.com (Nov. 3, 2015).

Jassem, Z. A. (2013i). The Arabic origins of "speech and writing" terms in English and European languages: A lexical root theory approach. Language in India 13 (5): 108-159. Retrieved URL: http://www.languageinindia.com (Nov. 3, 2015).

Jassem, Z. A. (2013j). The Arabic origins of "time words" in English and European languages: A lexical root theory approach. Language in India 13 (6): 274-97. Retrieved URL: http://www.languageinindia.com (Nov. 3, 2015).

Jassem, Z. A. (2013k). The Arabic origins of "family words" in English and European languages: A lexical root theory approach. International Journal of English and Education 2 (3): 261-77. Retrieved URL: http://www.ijee.org (Nov. 3, 2015).

Jassem, Z. A. (2013l). al'uSool al3arabiat lilDamaa'ir alshakSiat fi alingleeziat, walfiransiat, walalmaniat (The Arabic origins of "personal pronouns" in English, German, and French: A lexical root theory approach (In Arabic). Almu'tamar aldawli althamin, tajdeed alkhiTaab al3arabi, jaami3at imam bonjul, Indonesia 28-31 Nov. 2013 (8 ${ }^{\text {th }}$ International Conference of Arabic Speech Renewal, Imam Bonjul University, Indonesia, 28-31 Nov. 2013). Retrieved URL: http://www.academia.edu (Nov. 3, 2015).

Jassem, Z. A. (2013m). The Arabic origins of "cutting and breaking words" in English and European languages: A lexical root theory approach. Research Journal of English Language and Literature 1 (2): 155-68. Retrieved URL: http://rjelal.com (Nov. 31, 2015).

Jassem, Z. A. (2013n). The Arabic origins of "movement and action words" in English and European languages: A lexical root theory approach. Research Journal of English Language and Literature 1 (3): 187-202. Retrieved URL: http://rjelal.com (Nov. 1, 2015).

Jassem, Z. A. (2013o). The Arabic origins of "perceptual and sensual words" in English and European 
languages: A lexical root theory approach. Research Journal of English Language and Literature 1 (4): 212-24. Retrieved URL: http://rjelal.com (Nov. 3, 2015).

Jassem, Z. A. (2013p). The Arabic origins of "cognitive and mental words" in English and European languages: A lexical root theory approach. International Journal of English and Education 2 (4): 65-83. Retrieved URL: http://www.ijee.org (Nov. 1, 2015).

Jassem, Z. A. (2013q). The Arabic origins of "love and sexual words" in English and European languages: A lexical root theory approach. International Journal of Language and Linguistics 1 (4): 97-114. Retrieved URL: http://www.ijll.org (Nov. 1, 2015).

Jassem, Z. A. (2014a). The Arabic origins of "wining and dining words" in English and European languages: A lexical root theory approach. International Journal of English and Education 1 (4): 146-74. Retrieved URL: http://www.ijee.org (Nov. 3, 2015)

Jassem, Z. A. (2014b). The Arabic origins of "question and auxiliary words" in English and European languages: A lexical root theory approach. International Journal of Language and Linguistics 2 (1). Retrieved URL: http://www.ijll.org (Nov. $3,2014)$.

Jassem, Z. A. (2014c). The Arabic origins of "prepositions and conjunctions" in English and European languages: A lexical root theory approach. Journal for the Study of English Linguistics 2 (1). Retrieved URL: http://www.jsel.org (Nov. 1, 2015).

Jassem, Z. A. (2014d). Translating cultural universals radically: A lexical root theory approach for translating English, French, and German cultural terms into Arabic. Paper presented at International Conference on Translation and the Problematics of Cross-Cultural Understanding, the Forum for Arab and International Relations, Doha, Qatar 26-27 February 2014.

Jassem, Z. A. (2014e). The Arabic origins of "divine and theological terms" in English, German, and French: A lexical root theory approach. Language in India 14 (3): 155-195. Retrieved URL: http://www.languageinindia.com (Nov. 1, 2015).

Jassem, Z. A. (2014f). The Arabic origins of "proper names" in English and European languages: A lexical root theory approach. Research Journal of ELT and Poetry 2 (2): 201-22. Retrieved URL: http://www.journalofelt.in (Nov. 3, 2015).

Jassem, Z. A. (2014g). The Arabic origins of "mathematical and computational terms" in English and European languages: A lexical root theory approach. International Journal on Studies in English and Literature 2 (5): 21-40. Retrieved URL: http://www.arcjournals.org/ijsell (Nov. 3, 2015).

Jassem, Z. A. (2014h). The Arabic origins of "Mandarin Chinese Pronouns": A radical linguistic theory approach. International Journal of English and Education 3 (3). Retrieved URL: http://www.ijee.org (Nov. 3, 2015).

Jassem, Z. A. (2014i). The Arabic origins of "Finnish and Basque Pronouns": A radical linguistic theory approach. Journal of English language and literature 2 (1): 109-20. Retrieved URL: http://www.jellonline.com (Nov. 3, 2015).

Jassem, Z. A. (2014j). The Arabic origins of English and Indo-European "colour and artistic terms": A radical linguistic theory approach. International Journal of English language, literature, and Translation 1 (1): 1-14. Retrieved URL: http://www.ijels.com (Nov. 3, 2015).

Jassem, Z. A. (2014k). I buy, Ich kaufe, \& J'achéte as Arabic Dialectal Variants: A radical linguistic theory approach. International Journal of language and linguistics 2 (5): 317-27. Retrieved URL: http://www.sciencepublishinggroup.com/ijll. Doi: 10.11648/j.ijll.20140205.15 (Nov. 3, 2015).

Jassem, Z. A. (2014l). Radical translation and translating names: A lexical root theory approach. Paper to be presented at ASELS International Conference 2014, Abdel Malek Essadi University, Tangier, Morocco, 25-27 November 2014.

Jassem, Z. A. (2015a). The Arabic origins of English and Indo-European "life and death terms": A radical linguistic theory approach. International Journal of English and Education 4/1: 322-345.

Retrieved URL: http://www.ijee.org (Nov. 1, 2015).

Jassem, Z. A. (2015b). Towards a radical translation theory for names: A comparative historical linguistics approach. International Journal of English and Education 4/1: 298-321. Retrieved URL: http://www.ijee.org (Nov. 31, 2015).

Jassem, Z. A. (2015c). The Arabic origins of English and Indo-European "medical terms": A radical linguistic theory approach. Journal of English Language and Literature 2/1: 18-47. Retrieved URL: http://www.joell.in (Nov. 3, 2015).

Jassem, Z. A. (2015d). The Arabic origins or cognates of English and Indo-European "case markings and word order": A radical linguistic theory approach. Language in India 15/3: 104-40. Retrieved URL: http://www.languageinindia.com (Nov. 3, 2015).

Jassem, Z. A. (2015e). The Arabic origins of English and Indo-European "democratic terms": A radical linguistic theory approach. Journal of English Language and Literature 2/2: 111-139.

Retrieved URL: http://www.joell.in (Nov. 31, 2015).

Jassem, Z. A. (2015f). The Arabic origins of English and Indo-European "military terms": A radical linguistic theory approach. Language in India 15/5: 105-139. Retrieved URL: http://www.languageinindia.com (Nov. 12, 2015).

Jassem, Z. A. (2015f). The Arabic origins of English and Indo-European "legal terms": A radical linguistic 
theory approach. Journal of Applied Linguistics and Translation 1/3. Retrieved URL:

http://www.languageinindia.com (Nov. 3, 2015).

Jassem, Z. A. (2015g). The Arabic origins of English and Indo-European "urban terms": A radical linguistic theory approach. English Review: Journal of English Education 3/2: 146-66. Retrieved URL:

http://www.journal.uniku.ac.id/index.php/ERJE E/index (Nov. 3, 2015).

Jassem, Z. A. (2015h). Allugha alarabia wallugha alalamia aljadhria alwaritha al2afiDha: asmaa alishara fi lughat alalam qadeeman wa2adeethan min maDhoor 3ilm allugha aljadhri (in Arabic, Demonstrative Pronouns in World Languages: A Radical Linguistic Theory Perspective). Paper to be presented at Almultaqa al3ilmi al3alami altasi3 lillugha alarabia walmu'tamat alkhamis li-ittihad mudarisee allugha alarabia, entitled allugha alarabia asas althaqafa alinsania, Indonesia 2729 Nov. 2015 (9th International Conference of Arabic as Basis of Human Education, Imam Maulana Malik Ibrahim Government Islamic University, Indonesia, 27-29 Nov. 2015). Retrieved URL: http://www.academia.edu (Nov. $3,2015)$

Jassem, Z. A. (2015i). Negation in world languages: A radical linguistic theory approach. Veda's Journal of English Language and Literature 2/4: 1-17. Retrieved URL: http://www.joell.in (Nov. 25,2015 )
Langendoen, Terrence and Fabian, C. M. (2015). Yaqui nominal paradigms and the theory of paradigmatic structures. Retrieved URL: http://www.dingo.sbs.arizona.edu (November 11, 2015)

Pyles, T. \& J. Algeo. (1993). The origins and development of the English language. (4th edn). San Diego: $\mathrm{HBJ}$.

Roach, P. (2008). English phonetics and phonology: A practical course. (4th edn). Cambridge: Cambridge University Press.

Ruhlen, M. (1994). On the origin of languages: Studies in linguistic taxonomy. Stanford: Stanford University Press.

The World Atlas of Language Structures Online. 2015. Retrieved URL: http://www.wals.info (October 3, 2015).

Venla: Finnish for Foreigners. 2015. Retrieved URL: http://www.venla.info/grammar-nomines.php (October 3, 2015).

Wikipedia.org. (2015). Swadesh's list. Retrieved URL: http://www.wikipedia.org (Nov. 30, 2015).

Www.cromwell-intl.com. (2015). Basics of Turkish grammar. Retrieved URL: http://www.cromwellintl.com/turkish/nouns.html (Nov. 3, 2015).

Www.mylanguages.org. 2015. Korean plural. Retrieved URL: www.mylanguages.org/korean plural.php 2015 (Nov. 3, 2015).

Wiktionary.org. (2015). Swadesh's list. Retrieved URL: http://www.en.wiktionary.org (Nov. 3, 2015).

Yule, G. (2014). The study of language. ( $5^{\text {th }} \mathrm{ed}$.) Cambridge: Cambridge University Press. 